\title{
Discussion of Robot Application Laboratory Construction
}

\author{
Dongshu Wang ${ }^{1}$, Jiaming Chen ${ }^{1}$ and Lei Liu ${ }^{2}$ \\ ${ }^{1}$ School of Electrical Engineering, Zhengzhou University, Henan Zhengzhou, \\ China, 450001 \\ ${ }^{2}$ Department of Financial Research, The People's Bank of China, Zhengzhou Sub- \\ Central Branch, Zhengzhou, China, 450040. \\ wangdongshu@zzu.edu.cn,761958489@qq.com,luckyliulei@126.com
}

\begin{abstract}
Robot is a typical mechatronics product and the best teaching and research platform for the students in automated control, electric information, mechanical engineering, sensor and measuring technology, computer hardware and software, artificial intelligence, etc. In the background of emphasizing "engineering education should return to engineering itself", this work discusses the thought and background, constructing principles, constructing goal and constructing plan of the robot engineering practice innovation laboratory in university engineering courses. Its final goal is to widen the students' comprehensive domain knowledge, develop multi intelligences, improve their innovation, practice and the ability of self-constructing knowledge.
\end{abstract}

Keywords: Robot, Engineering Practice, Innovation Experiment, laboratory Constructing

\section{Introduction}

Robot is a multi-disciplinary cross and comprehensively high technology, which has important strategic influence to the national economy and security, and has wide market and good application prospect. It has been widely applied in the automotive, electronics, automation, petrochemicals and other industries. Nowadays, it is developing towards the fields of education [1-5], entertainment [6], the aged and disabled assistance [6], museum [7], hazardous environment working, etc., and now, it is forming a huge industry. Demands for research and development engineers, field engineers in the design, integration, installation, maintenance, and operation of the robot and the automatic production line are very urgent, thus it puts forward higher demands and challenges for the teaching method and effect of robots and automation.

With the transformation and upgrade of China's manufacturing industry, now, China is becoming a strong manufacturing country from a big manufacturing country. To guarantee the product quality and efficiency, as a kind of high technology and high valueadded important basic equipment, industrial robot is playing more and more important role in the automotive industry, aviation manufacturing, electronic assembly, modern logistics and other large-scale production. In the world wide, the average annual increasing rate of industrial robot is about 5-8\%, while in China and other Asian countries, it is about $20-25 \%$ [8].

Since robot is one kind of high-technical equipment, a large number of professional and technical personnel are needed in the process of design, manufacture, installation, commissioning, operation and maintenance. With increasingly wide applications and rapidly rising of installed capacity in robot, demand for this kind of technical personnel is becoming more and more urgent. In the past, robot research in China was mainly limited in the colleges, universities and research institutions, and it is mainly concentrated in 
scientific research. There exists severe lack of such talents in industrial field, which has become one of the bottlenecks in the application and popularization of the robot. So it becomes very urgent for the staffs to take part in the theory education, operation training and maintenance practice.

At present, many universities use the imported industrial robots as the teaching and experiment equipment. But it is difficult to meet the requirements of the teaching and experiments due to a series of problems. The general problems are described as follows:

(1) Openness is not enough because of keeping the technical secrets and reliability, so it is difficult to grasp the robot internal principle. In addition, its internal structure is invisible, thus making the teaching lack of intuitive effect; its external interfaces are limited, which greatly affect the teaching effect and make it unfit for the secondary development;

(2) Not optimized for teaching, and lack of a complete set of the matching teaching materials, so it is difficult to develop the curriculum further;

(3) Participation rate is low. Since the indices of speed, acceleration and load are high, danger should be strictly guarded against, therefore teaching is prone to transfer into view from training;

(4) Purchasing cost and maintenance cost is relatively high, which makes it not suitable for bulk purchase.

These reasons mentioned above make the relevant teaching and training enterprises become more and more cautious during buying the industrial robots, thus make the teaching lack of experiment and put more importance on theory instead of practice, which violate the original intention of robot education. Therefore, for the purpose of theory teaching with practice operation, research and develop the modular, low cost, open and visual robot which can embody the basic theory and technology of the industrial robots, is very urgent at present.

\section{Necessity of the Robot Education}

The United States, Korean, Japan and other developed countries hold optimistic opinion on the effect of robot education in the future high-tech society. They educate the students with robot from the elementary and middle schools to higher vocational colleges [9]. In order to keep up with the international standards and meet the coming era of robots, we must develop the robot education rapidly. At present, the domestic universities and vocational colleges have carried out the robot education successively. With the further development of robot technology, more and more robots will enter the classrooms, thus more and more students will become friends with the robots. Facing the rapid development of the robot education, if we don't take timely measures to implement the robot education among both the teachers and students, we will face a serious lack of talents and teacher teams of robots quickly.

Robot is a typical electromechanical integration equipment. It integrates the mechanical design, servo control, electronic and electrical engineering, control method and sensor technology, and can be used as a good practical teaching platform [10, 11]. At the same time, the actions of robots and automatic production line are complex, and they are modular and reconfigurable, easy to be set of group line, and flexible to use. So it can do a variety of practical teachings, besides, it is more cost-effective than general teaching equipments.

\section{Significance of Robot Application Laboratory Construction}

Construction of the robot application laboratory will promote students' practical ability and cultivate their creative consciousness. In order to supply the students with comprehensive capacity to the enterprises and society, cultivate an in-depth understanding of the robot technology for the students majoring in the mechanical 
and electrical engineering, enable students to master the practical skills and application tips of the robot technology, photoelectric detection, structural principle, calculation method, hands-on operation and assembly, fault detection and exclusion techniques and other aspects, enhance students' ability to integrate the design of mechanical and electrical products with advanced robot technology, bring students more competition advantages in the employment, establishing the robot application laboratory is imperative. Meanwhile, it is also the need of better development of the universities.

Construction of the robot laboratory is based on the domestic and foreign robot teaching concept to focus on the promotion of teaching and the team of teachers, and display the results of robot technology in the teaching efficiently[12, 13]. Introducing various types of robots can enrich students' professional knowledge, provide professional skills, and make them grasp the robot application and integration techniques in industrial enterprises. At the same time, it can greatly enhance the core competition ability of the universities, and has important significance in training and developing the teaching and scientific research personnel and cultivating the students' innovation ability and practical ability [14, $15]$.

\section{Feasibility Analysis of the Robot Application Lab Construction}

\subsection{Overall Goal of the Robot Application Laboratory Construction}

Robot application laboratory construction will be divided into two or three phases. In the first phase, we order the robot device suitable for the teaching, from the cooperative enterprise. We will do some experimental teaching trainings and the cooperation training between the university and the enterprise, then summarize the experiences. And the mutual inspection will be executed between the university and the cooperative enterprise. Looking to the future, according to the personnel training plan of cooperative enterprises, we will order the robot devices for the mechanical and the electrical teaching which are suitable for the university teaching concept, when time is right.

Overall goal of constructing the robot application lab is to construct the domestic firstclass training base for the middle and high level skilled personnel and the vocational skill appraisal base, which has the local characteristics and has the influence in the whole nation. Based on Henan province, the robot laboratory doesn't only meet the needs of the local vocational skill training, but will also be an important base for the research and practice of the occupation training, to affect the province and even the nation. And it also services for the robot training of the social enterprises and other techniques at the same time.

\subsection{Cultivating Goal of the Students}

Table 1. Cultivating Goal of the Students

\begin{tabular}{|l|l|l|}
\hline \multicolumn{2}{|c|}{ Position/Task } & \multicolumn{1}{|c|}{ Bachelor } \\
\hline $\begin{array}{l}\text { Research and design of robot, } \\
\text { system assembly and } \\
\text { debugging }\end{array}$ & $\begin{array}{l}\text { Master at least one skill of } \\
\text { design (mechanical design, } \\
\text { electrical design, software } \\
\text { design, etc.) or tool. }\end{array}$ & $\begin{array}{l}\text { Familiar with all kinds of } \\
\text { robots, automation equipment } \\
\text { etc. Lead the research and } \\
\text { development of large } \\
\text { electromechanical integrated } \\
\text { equipment. }\end{array}$ \\
\hline $\begin{array}{l}\text { Robot workstation and } \\
\text { automatic production line }\end{array}$ & $\begin{array}{l}\text { Master the common used } \\
\text { equipment, and skill of heat }\end{array}$ & $\begin{array}{l}\text { Design out the reasonable } \\
\text { technical route and technical }\end{array}$ \\
\hline
\end{tabular}




\begin{tabular}{|l|l|l|}
\hline $\begin{array}{l}\text { system integration, } \\
\text { installation, programming, } \\
\text { commissioning, operation and } \\
\text { maintenance }\end{array}$ & $\begin{array}{l}\text { treatment and surface treatment } \\
\text { method. } \\
\text { Can carry out some } \\
\text { engineering design in some } \\
\text { aspects (mechanical, electrical, } \\
\text { control, software engineering) } \\
\text { for the robot and automation } \\
\text { equipment. And complete the } \\
\text { total engineering drawings. }\end{array}$ & $\begin{array}{l}\text { lavility and team management } \\
\text { ability. } \\
\text { ability, knowledgeable, and } \\
\text { can foresee the development } \\
\text { direction of the enterprise's } \\
\text { new product. }\end{array}$ \\
\hline $\begin{array}{l}\text { Sales and after sale service of } \\
\text { robot }\end{array}$ & $\begin{array}{l}\text { Have strong summarize ability } \\
\text { and good at communication } \\
\text { and guidance with the site } \\
\text { commissioning staff and } \\
\text { customers on the equipment } \\
\text { installation, commissioning } \\
\text { and maintenance. }\end{array}$ & $\begin{array}{l}\text { Master the advanced } \\
\text { simulation analysis method } \\
\text { and tools, all kinds of } \\
\text { advanced control methods and } \\
\text { algorithms. }\end{array}$ \\
\hline
\end{tabular}

\subsection{Project Teaching Modes}

(1) Optimize the course system, and meet the training objectives and the requirements of the undergraduates and the graduates. Design and optimize the teaching system according to the goal of the professional ability cultivation, eliminate some redundant content, and increase the content of core competence cultivation.

(2) Take the market as the guidance, take the training of the professional competence of students as the standard, and the professional comprehensive quality of students as the goal. Through investigating and surveying various companies which use the robots, formulate the corresponding professional competence graph, establish the curriculum system according to the professional competence graph.

(3) Integrate the theory and the practice content for all core professional courses base on the pragmatism principle.

(4) Implement the modular teaching according to the students' ability cultivation claim. Divide the technology curriculum system into five basic capability modes, i.e., basic quality and ability, application capabilities, operation ability, the ability of maintenance, diagnosis and repair, and computer-aided design.

(5) Strengthen practical training teaching. Ratio of theory and practical training is about 1:1.

(6) Adopt the advanced teaching means to teach, and consummate the multimedia library gradually. All classrooms will apply the multimedia teaching gradually.

(7) Through cooperating with the robot enterprises, strengthen the rationality of the system equipment for designing the teaching plan.

\subsection{Guarantee Mechanism of the Project}

(1) Systematic supervision for the teaching

For the robot laboratory project and the future laboratory teaching work, leading group for comprehensive assessment will be set up to supervise and control the teaching quality effectively during the whole process. We will establish the teaching evaluation methods and determine the inspection requirements, contents, methods, and procedure. Teaching supervision and inspection will be carried out in each semester, appraisal and evaluation will be done at the final semester. Listening to the lecture, inspecting the lesson plans, checking the class work or training report randomly, checking the teaching log, and holding the seminars of the teachers and students behalf. All these manners will be the 
comprehensive examinations of the teachers' teaching attitude, teaching content and teaching method, knowledge level, work performance and teaching effect.

For the teachers, we will improve and perfect the evaluating system and the grading standards of the teaching quality further. Questionnaire survey, students evaluating the teachers, teachers' mutual assessment, quantitative score, and comprehensive evaluation will be conducted on the basis of the evaluation indices of the teaching assessment. Combined with the inspection of the middle semester, the evaluation score of every department will be calculated. Awards of the department will depend on the examination result. Each teacher will get the assessment respectively according to the school teacher assessment requirements, and personal quality award will connect with the examination result. Teachers with high quality, high academic level, large workload will get more benefits through the awards of the teaching evaluation and this will improve the teachers' enthusiasm on teaching and research.

(2) Double Teachers Teaching

Invite the enterprises to participate the whole procedure. Through the industry education association and committee of the professional construction consultant, the cooperating enterprises can take part in the whole teaching procedure. Annually, teachers will be organized to inspect the scene of enterprises to learn the status of the enterprise post setting and the knowledge and skills needed in each post, invite the cooperating enterprises' personnel to school to guide the teaching affair, and design the personnel training scheme together with the technical staff and management personnel from the enterprises. Through technology service and other ways, long-term mechanism of training the "double teacher" team will be established.

We will deepen the cooperation with the enterprises and achieve remarkable results in the fields of teacher training, the staff training, the students occupation ability development, science and technology development and services. Through cooperating with the enterprises, the university can cultivate more and more high skilled personnel.

\section{Considerations for the Robot Laboratory Construction}

Robot application laboratory construction goes from the easy to the difficult and complicated, from the smallest electromechanical simulation experimental platform to the comprehensive application of industrial robots, from technique imitation to technique innovation. The constructing procedure can be divided into two or three stages.

The laboratory can be divided into three areas to conduct a variety of experiments:

(1) Basic practical teaching area: as a basic part of the robot technique;

(2) Comprehensive application and practical training area: comprehensive training and maintenance for all types of industrial robot;

(3) Match and the exhibition area.

\subsection{Basic Practical Teaching Area}

(1) Multifunctional motor testing platform (Minimal mechanical and electrical system) shown as the Figure 1. 


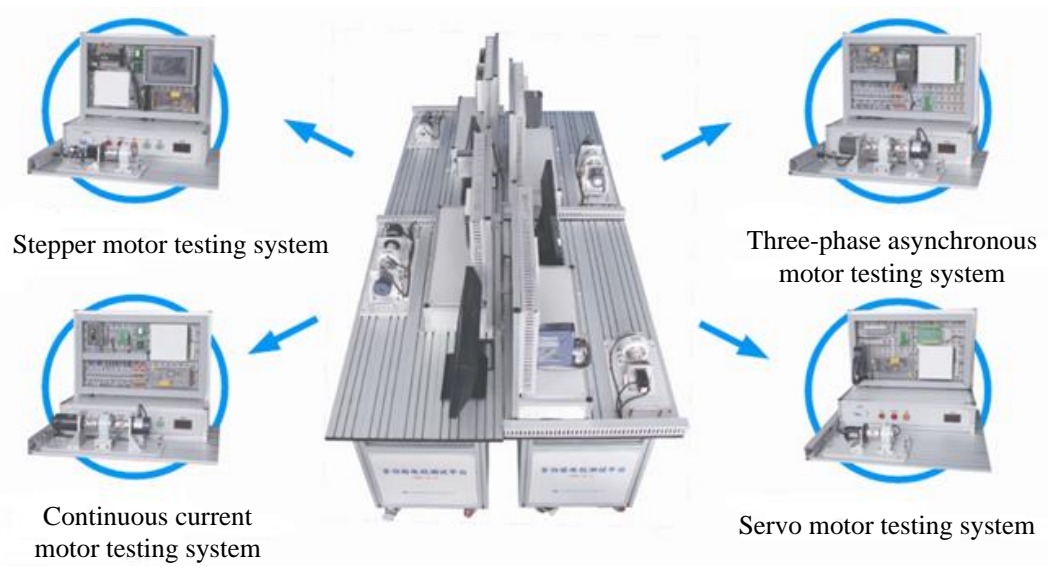

Figure 1. Multifunctional Motor Testing Platform

\section{Basic functions:}

Multifunctional motor testing platform can afford the separate experiments for 4-8 students. It can implement the basic training of motor principle and control, make the students master the basic knowledge of mechanical-electrical integration technology and the composition and principle of the minimal mechanical and electrical system, complete the application and performance test of various motors. It involves a variety of motors, drivers, controllers and other components of the basic mechanical and electrical system. It applies some kinds of basic control ways, such as special control card, PLC, frequency converting control, electronic speed control and other basic control modes. At the same time, the students can connect the electrical parts of the system personally and it enables them to fully grasp the system composition, basic principle and application during the design, assembly, test, etc.

Experiments can be conducted:

Designing experiments of the electrical control principle diagram of the mechanical and electrical system and the wiring diagram; disassembly-assembly and adjustment of each axis; mechanical-electrical system cable wiring; principle and control of the motion control card; principle and application of the rotary encoder; principle, application, maintenance and adjustment of the four kinds of motors (descried in Figure 1); principle and control of the motor driver; frequency converting speed control; principle and application of the man-machine interface; motor load and speed test; reading and curve plotting of the motor parameters; PLC programming control, etc.

(2) General training system of electromechanical integration precision machinery transmission, as depicted in Figure 2.

Basic functions:

(1) Cultivate students' ability to complete experimental tasks according to the characteristics of the motor and mechanical transmission, and train them the autonomous experiment ability. The system provides the motor models, as well as the information about the driver and test equipment. Students are asked to autonomously design and write down the experiment scheme according to the experiment task, establish the transmission system and test it, analyze the design scheme of the transmission system and write the experiment report finally.

(2) Master the basic requirements of the mechanical transmission reasonable layout and the general method of the mechanical transmission scheme designing. Moreover, the students can test the performance of the mechanical transmission system through such 
comprehensive experimental platform of the mechanical transmission, and analyze the characteristics of the mechanical transmission system.

(3) Master the working principle and the method of the comprehensive performance test of the mechanical transmission system through the experiment, and new methods of the computer aided experiment.

(4) Test the parameters change of the mechanical transmission device commonly used (such as belt drive, chain drive, gear drive, worm drive, cam drive, etc.,) during transmitting the motion and power. Deepen the comparison, recognition and understanding of the common mechanical transmission and the motor performance.

(5) Cultivate students' practical measurement ability, assemble, adjustment and the analysis ability of the physical object. And select the proper tolerance of error and apply the flexible and reliable design method to facilitate the adjustment and installation.

(6) Master the four different motors' performance, parameters, and comparisons of different transmissions and different speeds. Master the PLC programming and communication, and the motor speed governing techniques.

(7) Grasp the principles and application methods of the common sensors.

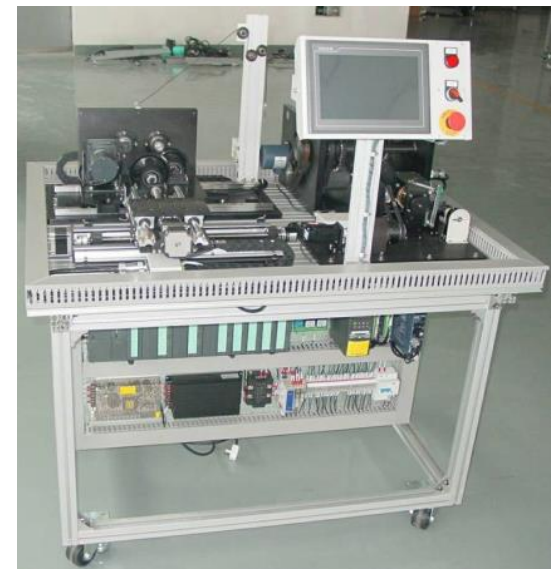

Figure 2. General Training System of Electromechanical Integration Precision Machinery Transmission

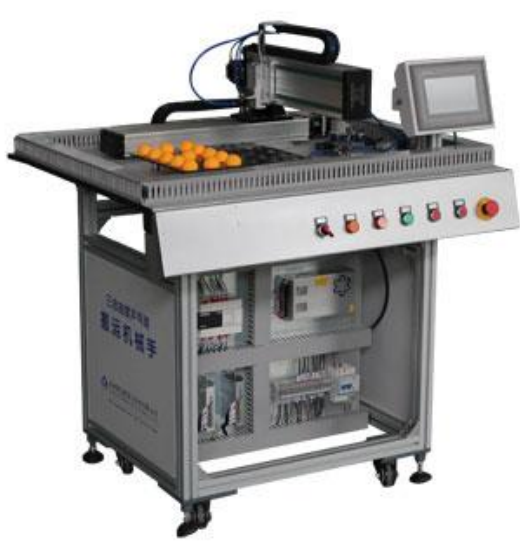

Figure 3. Three Axis Table Tennis Carry Robot

Experiments can be conducted:

Equipment cognition experiment; equipment installation and position adjustment; learning and maintenance experiment of the speed reducer and the transmission mechanism; wiring of electrical control cabinet; choose electric components; touch screen and the PLC programming and communication; principle and control of different types of motors; sensors experiment; linear interpolation experiment; equipment fault analysis, diagnosis and treatment of each unit of the system.

(3)Three axis table tennis carry robot, as shown in Figure 3.

Basic functions:

To train the students' practical ability and make them learn the PLC control and take part in the match. It's convenient for students to learn the robot physical structure and improve their interest to participate.

Experiments can be conducted:

Installation and position adjustment of mechanical device; composition, principle and connection of the vacuum adsorption; control experiment of the servo motor and stepper 
motor; cognition of electric components; pipeline connecting of the pneumatic components, linear drive of the pneumatic components, linear motion trajectory planning of two axis; electric control principle and wiring; principle and application of electromagnetic valve and vacuum generator; principle and application of optical fiber, photoelectric and magnetic sensor; PLC programming and application.

\subsection{Comprehensive Application and Practical Training Area}

(1) Modular, easy to disassemble and install, six degree of freedom series robot as shown in Figure 4.

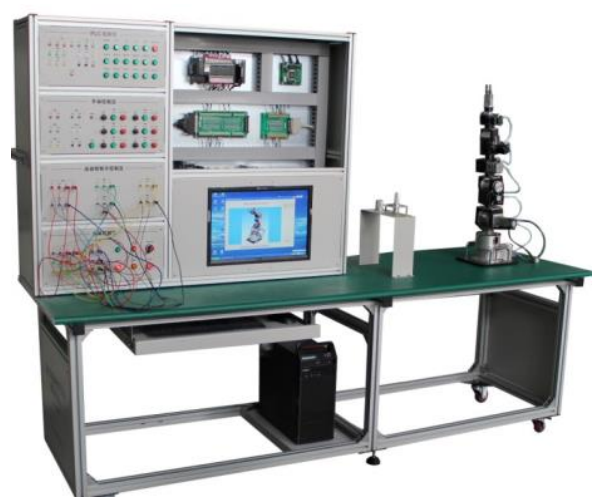

Figure 4. 6 DOF Series Robot

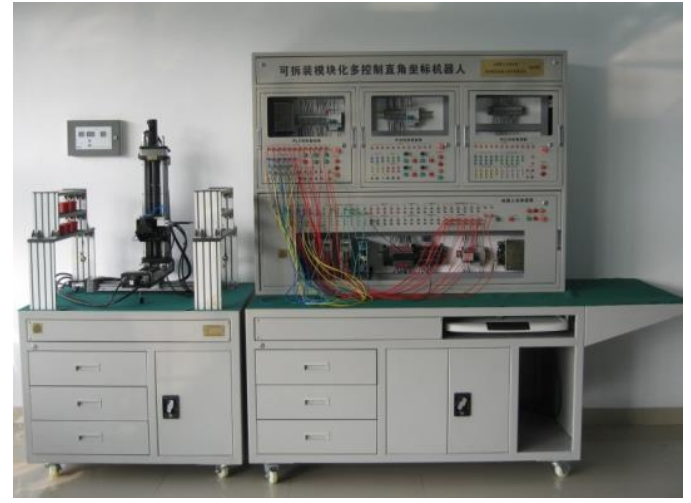

Figure 5. Cartesian Coordinate Robot

\section{Basic functions:}

Train the students' practical ability and the precision assembly ability, make students deeper understand the internal mechanical structure, internal connection, motors, reducer and transmission of the robots commonly used in the industrial field; train their ability to choose the series robot motors and reducer; control the robot with different control modes; electric wiring training, etc.

Experiments can be conducted:

Cognition of the robot; cognition of the robot mechanical system; cognition of the robot control system; robot teach programming and playback control; establishing the robot coordinate system; analysis of robot kinematics; analysis of robot inverse kinematics; the trajectory planning of robot joints; the trajectory control of robot point-topoint moving; the experiment of robot handling and assembly; VC, VB and other advanced language programming; independent moving experiment of the single module; disassembly and assembly of mechanical module; cognition and wiring of electric components; experiment of multi control conversion programming and operation.

(2) The Cartesian coordinate robot with multiple control methods, as shown in Figure 5.

Basic functions:

To train the students' practical ability and precise assembly ability, make students deep understand the internal mechanical structure, connection, motors, reducer and transmission of the robot commonly used in industrial field; train the ability to choose the motors and reducers of the Cartesian coordinate robot; using different control modes to control the robot; electric control wiring training, etc.

Experiments can be conducted:

Cognition of the experimental system: mechanical system, electrical system and action demonstration; encoder experiment; experiment of seeking zero position; experiment of 
point to point control; experiment of trajectory tracking system; linearity and verticality measurement of the working table; measurement of the repeatability; programming experiment under the windows environment; experiment of CNC machine tool simulation and $\mathrm{G}$ code programming; multi control experiments of the robot modules combination; experiment of PLC programming control.

(3) Standard four DOF SCARA robot system, as shown in Figure 6.

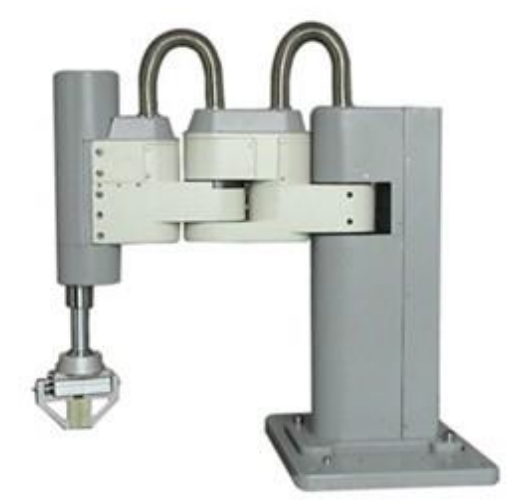

Figure 6. SCARA Robot System

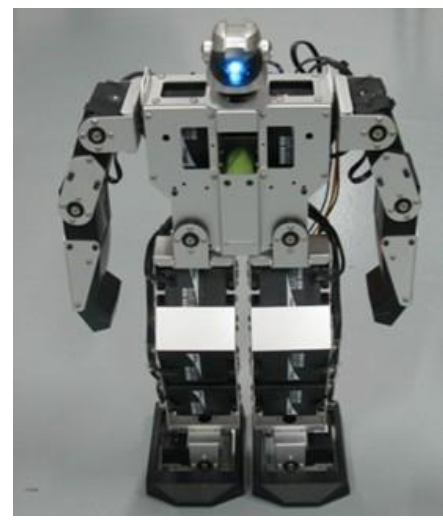

Figure 7. Humanoid Robot System

Basic functions:

Realize the plane multi joint parallel operating, and can meet the training requirements of the students.

Experiments can be conducted:

Handling and assembly experiment of the series robot; understanding the mechanical system of the series articulated robot; understanding the control system of the series articulated robot; teaching programming and playback control of the series articulated robot; building coordinate system of the series articulated robot; kinematics and inverse kinematics analysis of the series articulated robot; trajectory planning of the series articulated robot joint motion; trajectory control of the series articulated robot point-topoint motion; continuous path motion control of the series articulated robot; cognition of the series articulated robot; robot visual experiment and remote control experiment.

\subsection{Match and the Exhibition Area}

(1) The humanoid robot, as shown in Figure 7.

Basic functions:

Humanoid robot has the human shape characteristics. It is mainly composed of solid aluminum alloy as the support and has the strong rigidity. It can complete more than 200 kinds of actions. It is easy to repair and easy for students to design new actions. Relying on biped walking, the humanoid robot can stand, walk and act just like human. It can do all kinds of actions, such as push-up, walking, rolling forward, rolling back, lateral rolling, handstand, dance, martial arts, etc. It is mainly used in humanoid robot competition and the student training program. It can promote the students' interest in mechatronics and robots.

Experiments can be conducted:

Principle and application of the single chip microcomputer; bluetooth wireless technology; single chip microcomputer programming technology; structure and principle of steering engineering; steering engineering control technology; robot design and 
assembly; control technique of the humanoid robot; humanoid robot action arrangement and programming; computer network communication technology; robot balance technology; principle and application of the sensors.

(2) Intelligent tracked robot with crawlers for research, as shown in Figure 8.

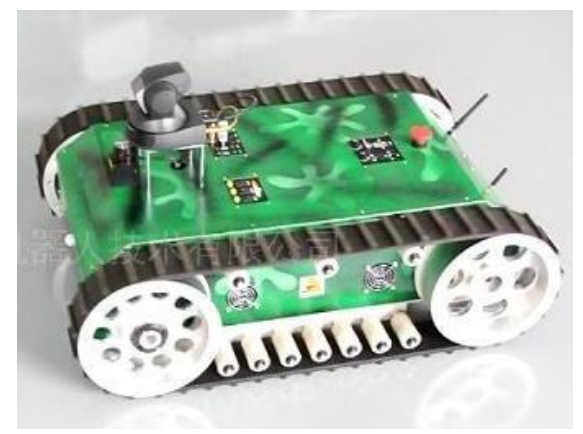

Figure 8. Intelligent Crawler-Type Research Robot

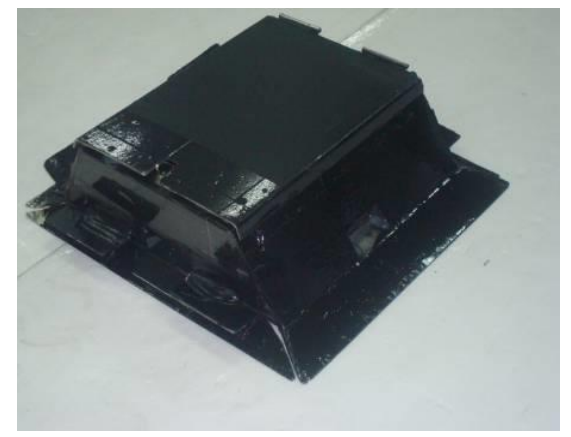

Figure 9. High Performance Competition Robot

Basic functions:

Robot with crawlers is a typical type of intelligent mobile robot. It integrates motion control, image processing, robot and other multi-disciplinary theory. It is an open and innovative experimental research platform. Users of this robot can equip it with manipulator arms, weapon equipments, fire-fighting equipment, rescue equipment and interactive humanoid language platform to control it remotely to do some handling, detection, rescue, riot police and other unmanned operation in dangerous environments. Robot with crawlers can be also used for the machine vision research and it takes more emphasis on the application. Equipped with the sensors of high precision servo control, infrared, vision, laser, ultrasonic wave sensors and so on, robot with crawlers has high application value in the teaching and scientific research.

Experiments can be conducted:

Navigation, obstacle avoidance and path planning research of the robot with crawlers; robot direction control algorithm; information fusion and processing of the robot multi sensor; visual information analysis and processing; image processing algorithm research in target extracting; specific target tracking research in a wide range; multiple targets tracking studies based on the background; robot remote distance network control.

(3) High performance competition robot, as shown in Figure 9.

Basic functions :

It accords with the rules of Chinese robot contest (Robocup open tournament), China robot martial arts challenge championship contest and no difference groups of China intelligent robot contest. Four adjustable grayscale sensors at the bottom of robot can recognize various color spaces and localize accurately and fast. Five infrared distance sensors around the robot can find the opponents quickly, and adjust the robot immediately which can guarantee a good performance of the robot. Challenge robot competition platform, mechanical and electrical system control, programming interface expansion.

Contests and experiments:

Chinese robot contest, i.e., Robocup open tournament; China robot martial arts challenge championship contest; no difference groups of China intelligent robot contest; 
single chip microcomputer control experiment; sensor experiment; design of the high performance arena contest robot.

\subsection{Team of Teachers}

Teachers are the most important part during the robot laboratory construction. As for robot laboratory and teaching practice, importance of the "software environment", such as the team of teachers and the policies to encourage the students, exceeds that of the "hardware environment", such as the lab equipment, space and the robot platforms.

Since the main function of the robot application laboratory is practical teaching, so the teachers must have the practical ability on robot teaching and experiments, and relevant teaching or contest experience is preferred. Here are the suggestions of the team of teachers:

(1) One full-time teacher with the robot related knowledge, is responsible for teaching and guiding students to practice. This teacher had better have the specialized subject, such as the mechanics, automation, electronics or other related disciplines. The teacher should have an in-depth understanding of the robot technology, and had better have engaged in the related competition or experimental works.

(2) 1-2 experimental guidance teacher(s) or teaching assistant(s) will be responsible for guiding the students to do the experiment and answering the students' questions. He or she can be the graduate with practical experience, and even the high grade undergraduate student who has taken part in the robot competitions. The specialized subject, such as the mechanical and electronics, measurement and control, automation, or other related disciplines, is preferred. He or she should be very skillful in the analysis and design of the circuit, and the digital circuit knowledge. In addition, he or she should master the microcontroller hardware development and $\mathrm{C}$ language programming, familiar with the complete development process.

\section{Conclusion}

The necessity, feasibility, principle, purpose and scheme of the construction of the robot application laboratory in engineering colleges are discussed in this work and we hope to provide some beneficial explorations to the construction of robot application laboratory in colleges and universities. The authors believe that construction of the robot application laboratory can promote the school teaching and scientific research, promote the transformation from the traditional teaching method to the project teaching method, at the same time, it can stimulate the students' interests in science and technology, cultivate the students' practical ability, innovation ability and team spirit of cooperation, and provide a broad platform to cultivate the comprehensive quality for the students.

\section{Acknowledgments}

The authors want to thank the support of the National Science Funds of China with grant no 61174085 .

\section{References}

[1] M. A. Tekerek. Human robot interaction application for robotic education. Procedia - Social and Behavioral Sciences, 1 (1), 2164-2169 (2009)

[2] O. Mubin, C. Stevens, S. hahid, A. Al Mahmud, and J.-J. Dong. A review of the applicability of robots in education. Technology for Education and Learning, 1, 1-7 (2013)

[3] V. Andreev, S. Kuvshinov, V. Pryanichnikov, and Y. Poduraev. Education on the basis of virtual learning robotics laboratory and group controlled robots. Procedia Engineering, 69, 35-40 (2014)

[4] B. Siciliano and O. Khatib, Editor, Robots for Education, Springer Berlin Heidelberg, Berlin, (2008)

[5] D. Alimisis. Educational robotics: Open questions and new challenges. Themes in Science \& Technology Education, 6 (1), 63-71 (2013) 
[6] R. D. Schraft, B. Graf, A. Traub, and D. John. A mobile robot platform for assistance and entertainment. Industrial Robot: An International Journal, 28 (1), 29 - 35 (2001)

[7] M. Shiomi, T. Kanda, H. Ishiguro, and N. Hagita. (2006). Interactive Humanoid Robots for a Science Museum. IEEE transactions on Intelligent Systems, 22 (2), 25-32 (2007)

[8] C. Yuan, L. Luo, Q. Yuan, J. Wu, R. Yan, H. Kim, K. Shin, and C. Han. Development and evaluation of a compact 6-axis force/moment sensor with a serial structure for the humanoid robot foot. Measurement, 70, 110-122 (2015)

[9] T. Kanda, R. Sato, N. Saiwaki, and H. Ishiguro. A two-month field trial in an elementary school for long-term human robot interaction, IEEE Transactions on Robotics, 23 (5), 962 - 971 (2007)

[10] V. Pryanichnikov, V. Andreev, P. Bobrov, E. Biryukova, A. Frolov, K. Kharin, K. Kirsanov, A. Kostin, S. Kuvshinov, Y. Marzanov, and E. Prysev. Scientific-educational distributed laboratory - software and hardware means. DAAAM International, 23 (1), 1175-1178 (2012)

[11] I. R. Nourbakhsh, J. Bobenage, S. Grange, R. Lutz, R. Meyer, and A. Soto. An affective mobile robot educator with a full-time job. Artificial Intelligence, 114 (1-2), 95 -124 (1999)

[12] B. Ladd and E. dan Harcourt. Student competitions and Bots in and introductory programming course. Journal of Computing Sciences in Colleges, 20 (5), 274-284 (2005)

[13] R. M. Felder and L. K. Silverman. Learning and teaching styles in engineering education. Engineering Education, 78 (7), 674-681 (1998)

[14] N. F. A. Zainal, S. N. H. Sheikh, and A. S. Prabuwono. Adapting robot soccer game in student selfentered learning. Procedia - Social and Behavioral Sciences, 59, 130-137 (2012)

[15] R. G. Simmons, D. Goldberg, A. Goode, M. Montemerlo, N. Roy, B. Sellner, and B. A. Maxwell. GRACE: An Autonomous Robot for the AAAI Robot Challenge. AI Magazine, 24 (2), 51 -72 (2003)

\section{Authors}

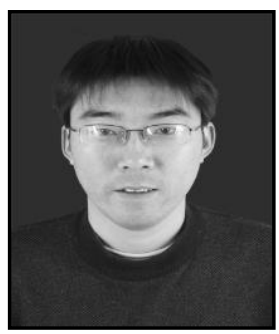

Dongshu Wang, received his Bachelors degree in Mechanical Manufacture Technique and Equipment in 1996, Masters degree in Mechanical Manufacture and Automation in 2002, and $\mathrm{PhD}$ in Control Theory and Control Engineering in 2006 from Northeastern University, China. His research domain is autonomous mental development and artificial intelligence. Currently, he is an Associate Professor in School of Electrical Engineering, Zhengzhou University, Zhengzhou, China.

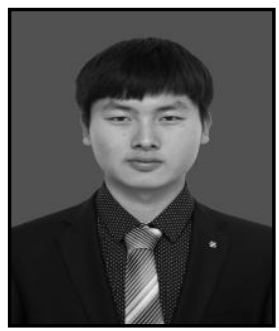

Jiaming Chen, received his Bachelors degree in Automation in 2015 Zhengzhou University, China. His research domain is autonomous mental development and artificial intelligence. Currently, he is a master in School of Electrical Engineering, Zhengzhou University, Zhengzhou, China.

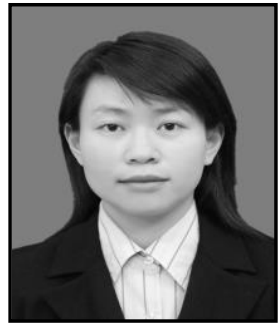

Lei Liu, received her Bachelor degree in Accounting in 1997 from Northeastern University, Master degree in Accounting in 2001 from Zhongnan University of Economics and Law, PhD in Quantitative Economics in 2008 from Huazhong University of Science and Technology. Her research domain is financial risk control and intelligent computation. Currently, she is a research associate professor in the Department of Financial Research, the People's Bank of China, Zhengzhou Central Sub-Branch, Zhengzhou, China. 